Niğde Ömer Halisdemir Üniversitesi Mühendislik Bilimleri Dergisi
Niğde Ömer Halisdemir University Journal of Engineering Sciences

\title{
Mansapta trapez daralma olması durumunda baraj yıkılması taşkın dalgası yayılımının sığ su denklemleri ile modellenmesi
}

\section{Modelling of dam break flood wave propagation in case trapezoidal contraction on downstream using SWEs}

\author{
Selahattin Kocaman'(D), Kaan Dal ${ }^{2 *(D)}$, Ada Yılmaz ${ }^{3}(D)$

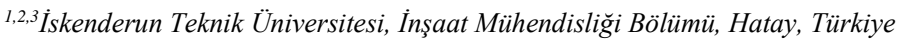

\begin{abstract}
Özet
Baraj yıkılması sonucu oluşan taşkın dalgası can ve mal kayıplarına sebep olabileceği için hidrolik alanında önemli bir çalışma konusudur. Ancak gerçek baraj yıkılması olayına ait veriler yetersizdir ve bu durum konu ile ilgili araştırmacıların bilgisini de sınırlamaktadır. Bu nedenle baraj yıkılması verisi üreten deneysel çalışmalar hem konunun daha iyi anlaşılması hem de nümerik ve analitik yöntemlerin doğrulanması için büyük önem taşımaktadırlar. Bu çalışmada, mansap bölgesinde trapez daralma bulunması durumundaki baraj yıkılması akımına ait yüzey profilleri ve noktasal su seviyesi değişimleri incelenmiştir. Verilerin karşılaştırılması deneysel ve sayısal olarak yapılmıştır. Sayısal veriler ücretsiz BASEMENT yazilımında bulunan 2 boyutlu sı ̆̆ su denklemleri yardımıyla elde edilmiştir. Riemann çözücü olarak ise tam çözücü kullanılmıştır. Deneysel sonuçlara ise görüntü işleme yöntemi aracılığ ile ulaşılmıştır. Sonuçların uyum içerisinde olduğu ve 2 boyutlu sığ su denklemlerine dayanan analizin mansapta trapez daralma bulunan bir baraj yıkılması problemini çözebilme kapasitesi olduğu gözlenmiş̧ir. Ayrıca bu yöntem, daha gelişmiş bilgisayar teknolojisi gerektiren 3 boyutlu Reynolds Ortalamalı Navier-Stokes denklemlerine kıyasla hızlı çözüm imkanı sunan kullanışlı bir yöntem olarak değerlendirilmiştir.
\end{abstract}

Anahtar kelimeler: Baraj yıkılması, Kesit daralması, Sı ̆ su denklemleri, Sayısal model

\section{Giriş}

Akışkanlar mekaniğinde düzenli olmayan akışların araştırılmasında baraj yıkılması olayı kayda değer bir yer tutmaktadır. Baraj yıkılması, gerçekleşmesi durumunda geniş çaplı felaketlere sebep olabileceğinden araştırmacıların ilgisini çeken bir konu olmuştur. Bu nedenle baraj yıkılması halinde mansapta su altında kalabilecek yerlerin önceden belirlenebilmesi ve erken uyarı sistemleri gibi çeşitli önlemlerin geliştirilebilmesi amacıyla sayısal ve deneysel çalışmalar yapılmaktadır. Bir barajın yıkılması halinde meydana gelecek taşkın dalgasının; taban eğimi, vadi topografyası, bitki örtüsü ve varsa yerleşim biriminin durumu gibi çok çeşitli mansap koşullardan etkilenmesi kaçınılmazdır. Genel olarak bu etkiler kendisini yansıyan

\begin{abstract}
Since the flood wave resulting from the dam-break can cause loss of lives and properties, it is a significant field in the hydraulic studies. However, researchers have limited knowledge regarding the phenomena due to the lack of the real case dam-break data. Experimental studies producing the dam-break data are important to better understand the problem and validate the numerical or analytical data. Surface profiles and water levels of a dam-break flow in the case of downstream contraction were analyzed in the present study. Experimental and numerical results were compared using free surface profiles and water level- time curves. 2D shallow water equations (SWEs) with exact Riemann solver inside the free BASEMENT software were employed to obtain the numerical results. Experimental results were acquired using image processing technique. It was concluded that the results agree well and model based on $2 \mathrm{D}$ SWEs is able to solve the dam-break problem in case trapezoidal contraction on the downstream. In addition, this method was considered as a useful method that offers faster and reliable solution compared to 3D Reynolds Averaged Navier-Stokes equations, which require more advanced computer technology.
\end{abstract}

Keywords: Dam break, Contraction, Shallow water equations, Numerical model

dalgalar, hidrolik sıçramalar ve ani şoklar olarak gösterebilmektedir. Kaotik akım koşullarının meydana geldiği böyle bir durumun sayısal olarak modellenmesi karmaşıktır ve deneysel çalışmalarla desteklenmesi gerekmektedir.

Yıkılma olayı sonucu membadan mansaba doğru ilerleyen kontrolsüz akımın özelliklerini etkileyen önemli unsurlardan birisi kesit daralmasıdır. Akarsudaki yapay veya doğal nedenlerle oluşan kesit daralması akımın karakteristiğinde büyük etkiye sahip olabilmektedir. Bu nedenle yıkılma olayı sonrası ortaya çıkacak akımın özelliklerini tespit etmek için mansap tarafındaki kesit daralmasının akımı nasıl ve ne kadar etkileyeceği iyi belirlenmelidir.

\footnotetext{
* Sorumlu yazar / Corresponding author, e-posta / e-mail: kaan.dal@iste.edu.tr (K.Dal)

Geliş / Recieved: 04.03.2021 Kabul / Accepted: 31.05.2021 Yayımlanma / Published: 27.07.2021

doi: $10.28948 /$ ngmuh. 825144
} 
Baraj yıkılması sebebi ile oluşan taşkın dalgasının analizi büyük ölçekli bir hidrolik problemdir. Bu tür problemlerin sayısal analizleri sirasında 3 boyutlu Reynolds Ortalamalı Navier-Stokes (RONS) denklemleri kullanılmaktadır. Bu çözümler için hassas sonuçlar elde edilmek istendiğinde ileri derecede gelişmiş bilgisayar teknolojisinden istifade edilmekte ve analizler birkaç aya varan uzun sürelerde yapılabilmektedir. Analizler için başvurulabilecek bir diğer yöntem ise sı̆̆ su denklemlerine (Shallow Water Equations, SWE) dayanan 1 ve 2 boyutlu çözümlerdir. Bu denklemlerin sayısal çözümleri, RONS denklemlerini kullanan 3 boyutlu çözümlere göre daha az işlemci gücü gerektirmektedir. Ayrıca analiz süreleri de kayda değer biçimde düşmektedir. Gerçek bir baraj yıkılması olayı 3 boyutlu olsa da, ideal koşullar sağlanarak problemin analizinde etkin olan kuvvetlerin 1 veya 2 boyuta indirgenmesi mümkün olabilmektedir. Bu durumda SWE kullanımı çözüm açısından önemli kolaylıklar sağlamaktadır. Denklemler su derinliğinin tespit edilmesi için çözülmekte ve çözüme yük olan su yüzeyinin konumunun belirlenmesi durumu ortadan kalkmaktadır. Diğer yandan, düşey yöndeki ivme bileşeni ihmal edilip basınç dağılımının hidrostatik olduğu varsayıldığı için denklemlerin çözümü sırasında ayrıca bir basınç hesabına da gerek kalmamaktadır. Bu gibi durumlar, özellikle çözümün sadeliği açısından SWE'nin diğer analiz yöntemlerine kıyasla üstünlükleri olarak gösterilebilmektedir. Ancak bahsedilen varsayımlar bazı problemlerin çözümünde kritik hatalara yol açabileceğinden SWE'nin kullanıminda ve yorumlanmasinda mevcut problem şartlarının göz önünde tutulması gerekmektedir. Bu çalışmada baraj yıkılması akımı ince ve uzun bir kanalda incelendiği için akım üzerinde 3 . boyut etkisinin diğer eksenlere kıyasla göreceli olarak az olacağı ve problemdeki baskın kuvvetlerin daralma bölgesi dışında iki eksende meydana geleceği kabul edilmiştir. Kendisine göre daha gelişmiş ve daha hassas çözümler yapabilen yöntemler bulunmasına rağmen, SWE bahsi geçen avantajlarından dolayı halen önemini kaybetmemiştir ve günümüzde pek çok araştırmacı tarafından yaygın bir biçimde kullanılmaktadır. Araştırmacıların elinde baraj yıkılması konusunda gerçek bir vakaya ait veriler olmadığ 1 için, sayısal analiz sonuçlarının doğrulanması ancak deneysel veriler ile mümkün olmaktadır.

Literatürde baraj yıkılması akımının düzensiz kanal koşulları için incelendiği deneysel ve nümerik pek çok çalışma bulunmaktadır. Kanal geometrisinde güçlü değişimlerin [1], deneysel ve sayısal olarak kesitte daralma etkisinin [2, 3], 2 boyutlu bir sayısal modelin daralan kesitli bir kanala uygulanmasının [4], düzensiz yatak topografyası için geliştirilen 2 boyutlu bir modelin daralan kesit problemine uygulanmasının [5] ve tabanda eşik bulunmasının deneysel ve sığ su denklemlerine dayanan nümerik analiz sonuçlarının karşılaştırılmasının [6] araştırıldığı çalışmalar yapılmıştır. Son zamanlarda görüntü işleme metodunun baraj yıkılmasına uygulandığı çalışmalar da yaygınlaşmaktadır [7-11]. Ayrıca görüntü işleme metodu ile daralan kanal kesiti içeren baraj yıkılması problemi de incelenmiştir [12].
Sığ su denklemlerine baraj yıkılması akımının analizlerinde yaygın şekilde başvurulmakta [13-16] ve son yıllarda farklı çözüm yöntemleriyle birlikte kullanılarak birleşik çözüm modelleri de geliştirilmektedir [17, 18]. Ayrıca literatürde ardışık baraj yıkılması akımının eğimli yatak koşullarında incelendiği çalışmalar da mevcuttur [19]. $\mathrm{Bu}$ çalışmada, eğimsiz ve kuru yatak şartlarında baraj yıkılması sonucu oluşan taşkın dalgasının mansap tarafında trapez şekilde daralan bir kesit bulunması durumunda yayılmasının deneysel verileri görüntü işleme yöntemi kullanılarak elde edilmiştir. Bu sonuçlar, iki boyutlu sı̆g su denklemlerini kullanarak çözüm yapan ve ücretsiz olan BASEMENT yazılımından elde edilen nümerik veriler ile karşılaştırılmıştır.

\section{Teori}

Sı ̆ su denklemleri, Navier-Stokes denklemlerinden düşey ivmenin ihmal edilmesi ile elde edilebilmektedir. Serbest yüzeyli akımlarda, akarsu taşkın analizlerinde, okyanuslardaki tsunami dalgasının ve baraj yıkılması taşkın dalgasının yayılması gibi problemlerin sayısal çözümünde yaygın biçimde kullanılmaktadır.

Sığ su denklemleri korunumlu ve korunumlu olmayan çeşitli formlarda ifade edilmektedir. Baraj yıkılması gibi içerisinde şok dalgası bulunduran problemlerin çözümünde korunumlu denklemler korunumlu olmayan formdan daha iyi sonuçlar vermektedir. BASEMENT yazılımı, korunumlu formda iki boyutlu denklemleri çözmektedir [20]. Bu denklemlerin sonlu hacimler yöntemi kullanılarak yapılan sayısal çözümü ile birbirine dik iki farklı doğrultudaki ortalama hız ve akım derinlikleri elde edilmektedir. Sistemin vektör formatındaki eşitliği aşağıdaki gibidir;

$$
U t+\nabla \cdot(F, G)+S=0
$$

Burada; U bağımlı değişkenlerin vektörüdür. Alt indis $\mathrm{t}$ zamana göre türevi göstermektedir. $F$ ve $G$ sirası ile $x$ ve $y$ doğrultularındaki akım, $S$ ise kaynak terimidir.

$$
\begin{gathered}
U=\left(\begin{array}{c}
h \\
u h \\
v h
\end{array}\right) \\
F=\left(\begin{array}{c}
u h \\
u^{2} h+\frac{1}{2} g h^{2}-v_{t} h \frac{\partial u}{\partial x} \\
u v h-v_{t} h \frac{\partial u}{\partial y}
\end{array}\right) \\
v=\left(\begin{array}{c}
u h \\
u v h-v_{t} h \frac{\partial v}{\partial x} \\
v^{2} h+\frac{1}{2} g h^{2}-v_{t} h \frac{\partial v}{\partial y} \\
0 \\
g h\left(S_{f x}-S_{B x}\right) \\
g h\left(S_{f y}-S_{B y}\right)
\end{array}\right)
\end{gathered}
$$

Burada; $h$ akım derinliği (metre), $u$ ve $v$ sirasıyla $x$ ve $y$ doğrultularındaki derinlik ortalamalı hız bileşenlerini $(\mathrm{m} / \mathrm{s})$, 
$S_{f x}$ ve $S_{f y}$ sirasiyla $x$ ve $y$ doğrultusundaki sürtünme eğimleri, $S_{B x}$ ve $S_{B y}$ sirasıyla $x$ ve $y$ doğrultularındaki taban eğimleri, $v_{t}$ kinematik viskozite $\left(\mathrm{m}^{2} / \mathrm{s}\right), g$ yerçekimi ivmesi $\left(\mathrm{m} / \mathrm{s}^{2}\right), x$ ve $y$ birbirine dik doğrultulardır.

\section{Materyal ve metod}

\subsection{Deney düzeneği ve yöntem}

Deneyler için boyutları 9x0.3x0.35 metre (uzunluk, genişlik, yükseklik) olan bir kanal kullanılmıştır. Barajı temsil eden düşey bir kapak, kanalı ilk 4.65 metresi memba, kalan 4.25 metrelik kısmını ise mansap olacak şekilde ikiye bölmektedir. Başlangıçta membadaki su yüksekliği 0.25 metre olarak alınmıştır ve mansapta kuyruk suyu bulunmamaktadır. Kanalın mansap ucu suyun boşalabilmesi için açık olarak bırakılmıştır. Kanalın taban ve yan yüzeyleri camdan yapılmış olup, kalınlığ1 0.01 metredir. 15 kilogram bir ağırlık kapağın ucuna çelik bir halat ile bağlanmış ve sabit yükseklikten serbest bırakılarak kapağın yukarı yönde ani yükselmesi sağlanarak baraj yıkılması taşkın dalgası oluşturulmuştur. (Şekil 1).

Her iki yan duvarda simetrik olarak barajin $1.52 \mathrm{~m}$ mansabında konumlandırılmış pleksiglastan yapılan trapez geometriye sahip engeller yardımıyla kanalda yerel bir daralma oluşturulmuştur. Kanal planı Şekil 2'de görülmektedir. Engelin uzunluğu $0.95 \mathrm{~m}$, daralma bölgesindeki açıklığa ait genişlik $0.10 \mathrm{~m}$ seçilmiştir.

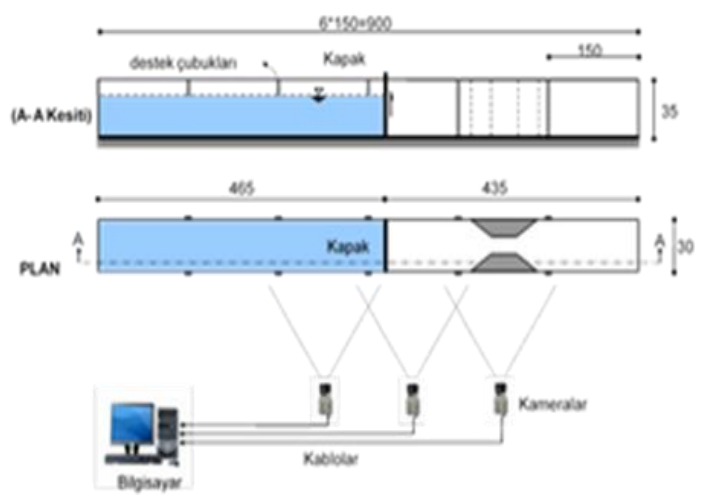

Şekil 1. Deney kanalının genel görünümü ve kamera konfigürasyonu [3] (birimler, $\mathrm{cm}$ )

Baraj yıkılması sonucu oluşan akım davranışının değerlendirilmesi için deney video kameralar ile kayıt altına alınmıştır. Su yüzü profillerinin ve belirli noktalardaki su seviyelerinin zamana bağlı değişimlerinin kaydedilen görüntüler üzerinden görüntü işleme teknikleri ile daha kolay belirlenebilmesi amacıyla rezervuardaki su gida boyası ile renklendirilerek su hava arakesitini oluşturan serbest su yüzeyi daha belirgin hale getirilmiştir.

Bu çalışmada, 3 adet CCD sensöre sahip kamera, 1 adet görüntü aktarıcı kart (frame grabber card) ve 1 adet bilgisayardan oluşan bir görüntüleme sistemi kullanılmıştır. Kameralardan gelen görüntüler eş zamanlı olarak aktarıcı kart aracılığ̣ ile bilgisayara gönderilmiştir. Sonraki aşamada senkronize çalışan 3 ayrı kameradan gelen görüntüler, kanalın mansabının panoramik görüntüsünü elde etmek amacıyla birleştirilmiştir. Su derinliklerinin hassas belirlenebilmesi için 768x576 piksel çözünürlüğe ve 50 fps (saniyedeki görüntü kare sayısı) çekim hızına sahip kameralardan elde edilen görüntüler kullanılmıştır. Belirli noktalardaki su seviyelerinin zamanla değişimlerinin belirlenmesi için $20 \mathrm{~s}$ süresince $0.020 \mathrm{~s}$ aralıkla çekilmiş 1000 adet görüntünün analizinden yararlanılmıştır. Kaydedilen ve kalibrasyonları yapılan bu görüntüler yardımıyla görüntü işleme teknikleri kullanılarak ölçümler gerçekleştirilmiştir. Farklı zamanlardaki su yüzü profilleri ve kanal boyunca farklı noktalarda zamana bağlı su seviyesi değişimleri sanal derinlik ölçer kullanılarak elde edilmiştir [15].

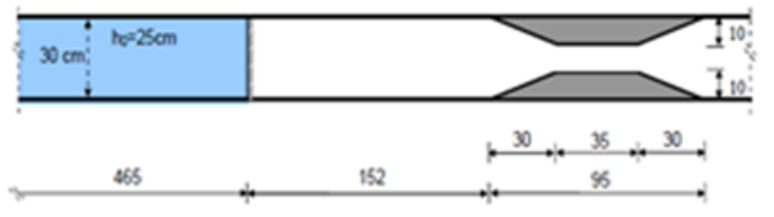

Şekil 2. Kanal planı [3]

\subsection{Nümerik Yöntem}

Baraj yıkılması sebebi ile oluşan taşkın dalgasını sı̆̆ su denklemleri ile sayısal olarak analiz etmek amaciyla BASEMENT yazılımı kullanılmıştır. ETH Zürich Üniversitesi'nde geliştirilen ve ücretsiz olan bu yazılım ile sığ su denklemlerine dayanan bir veya iki boyutlu akışkan problemleri sonlu hacimler yöntemi ile analiz edilebilmektedir [21].

Yazılımda, baraj yıkılması olayında meydana gelen şok dalgalarının sorunsuz çözümüne olanak tanıyan tam (exact), HLL ve HLLC Riemann çözücüler ile analiz yapmak mümkündür. Riemann problemi tam olarak çözülebilse de, daha kısa zamanda analiz yapabilen yaklaşık Riemann çözücüler de günümüzde yaygın olarak kullanılmaktadır. Bu çalışmada tam Riemann çözücü kullanılmış ve deney düzeneğinin boyutları bire bir oranında tanımlanmıştır. Problemin iki boyutlu olarak modellendiği bu çalışmada ağ aralıkları 0.01 metre seçilmiş ve Courant sayısı 0.1 olarak alınmıştır. Tabanda Manning pürüzlülük katsayısı 0.0095 seçilmiştir. Sınır şartı olarak ise kanal yan çeperleri duvar tanımlanmış ve mansap sınır şartı suyun deneydeki gibi serbestçe kanaldan uzaklaşabilmesi için "outflow” olarak belirlenmiştir. Çözüm 20 saniye için yapılmıştır.

\section{Bulgular ve tartışma}

Farklı zamanlara ait deney görüntüleri ve $t=3.5 \mathrm{~s}$ anında kanal boyunca oluşan akım rejimleri Şekil 3'de verilmiştir. Barajı temsil eden düşey kapağın ani olarak yukarı yöndeki hareketi ile birlikte oluşan taşkın dalgası hızlı bir biçimde trapez şekildeki daralan kısma doğru ilerlemiştir ( $t=0.9 \mathrm{~s}$ ). Kesit daralması ile karşılaşan akımın bir kısmı daralan kesitte ilerlerken bir kısmı da kesitten geçemeyerek memba yönüne doğru ilerleyen negatif bir dalga oluşturmuştur $(t=1.2-2.7 \mathrm{~s})$. Şekil 3'de görüldüğü gibi taşkın dalgası engelin varlığı nedeniyle daralma noktasına ulaştığında çarpmanın da etkisiyle hızını kaybetmektedir. Daralan kesiti geçmesi için gereken özgül enerjiyi su seviyesinin kabarmasıyla sağlayan dalga, daralmış kesiti geçtikten sonra hızını tekrar arttırmaktadır. 

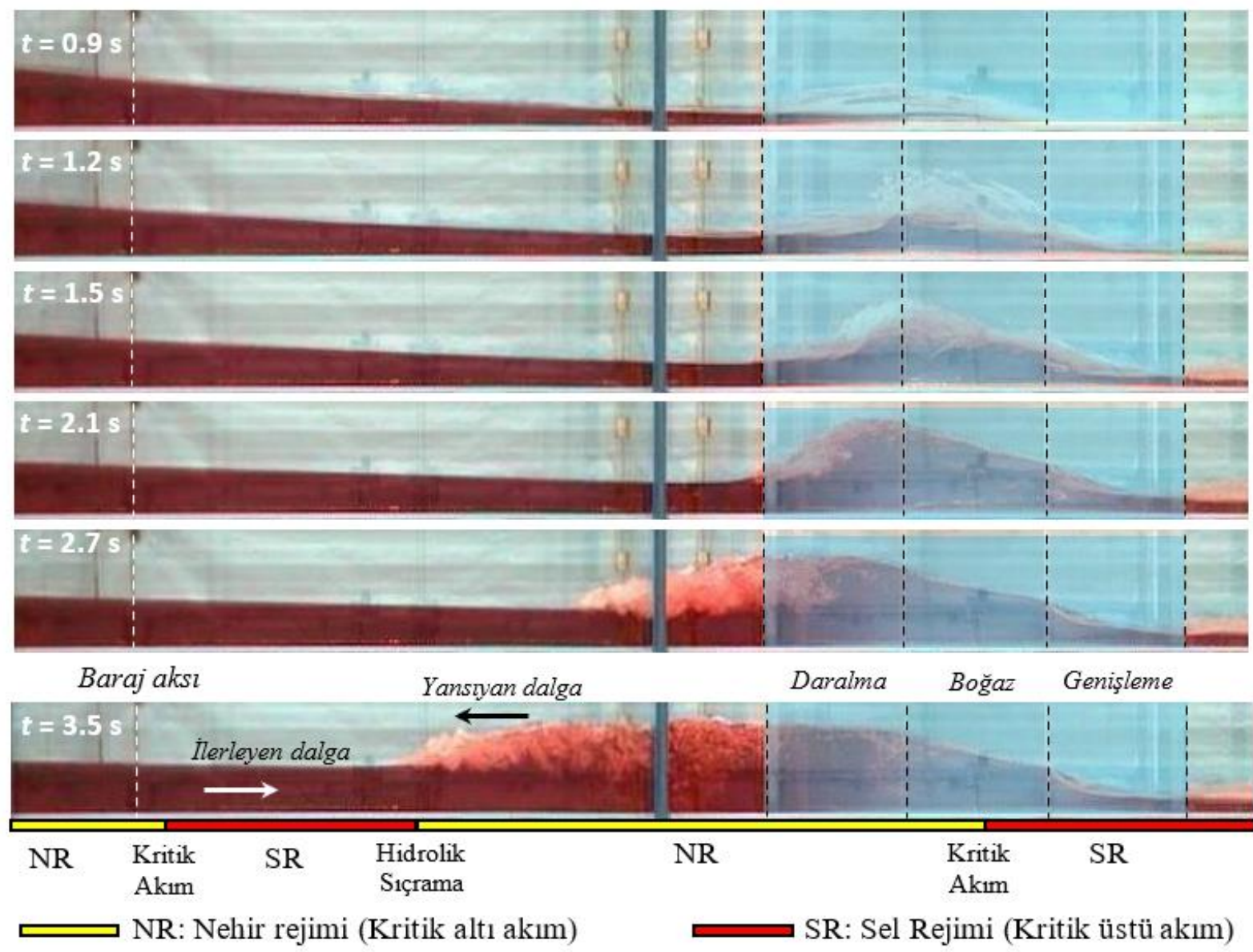

Şekil 3. Farklı zamanlara ait deney görüntüleri ve $t=3.5 \mathrm{~s}$ anında kanal boyunca oluşan akım rejimleri

Baraj yıkılmasından dolayı meydana gelen taşkın dalgasının özgül enerjisinin en dar kesitteki minimum enerji seviyesine çıkması gerekmektedir. Bu durum ise ancak kesitin en dar kısmının membasındaki su seviyesinin artışı ile mümkün olabilmektedir. Su seviyesinin yükselmesi ile daralan bölgede akım nehir rejimine geçmektedir. Daralan enkesite doğru ilerleyen sel rejimindeki akım ile daralma bölgesi içerisindeki nehir rejimine geçen akım arasındaki geçiş sırasında hidrolik sıçrama meydana gelmektedir $(t=2.7 \mathrm{~s})$. Kesitin daralan kısmında bulunan suyun belli bir seviyeye yükselmesinden sonra memba tarafına doğru ilerleyen hareketli hidrolik sıçrama olarak da adlandırılabilecek negatif bir dalga hareketi oluşmaktadır $(t=2.1-3.5 \mathrm{~s})$.

Deney sırasında yapılan gözlemlere göre bu aşamada daralan kesitin orta noktası civarında su yüksekliği maksimuma ulaşmış ve yüzeyde tümsek şeklinde bir su yüzü profili oluşmuştur $(t=2.1 \mathrm{~s})$. İlerleyen ve engelden yansıyan dalgaların çarpışması sonucunda daralmanın memba kısmında meydana gelen hareketli hidrolik sıçrama güçlü hava girișimlerinin olduğu bir akım ortamına neden olmaktadır $(t=2.7 \mathrm{~s})$. Ayrıca memba yönünde hareket eden dalganın önünde bulunan bu hava girişiminin zamanla azaldığ 1 da gözlenmiştir ( $t=3.5 \mathrm{~s})$. Bu durumun sebebi, barajın yıkılması ile birlikte ilk anda yüksek bir debiye sahip olan ve mansap yönünde ilerleyen taşkın dalgasının rezervuardaki suyun boşalmasına bağlı olarak zamanla akımın gücünü yitirmesi ve yansıyan dalga ile çarpışma şiddetinin azalması ile açıklanabilir. Başlangıçta yüksek enerjiye sahip taşkın dalgasının yansıyan dalga ile çarpıșması ile önemli enerji kayıpları yaşanırken zamanla debinin düşmesi ile birlikte taşkın dalgasının özgül enerjisi azalmakta ve bir yandan da akımın daralan bölgeden savaklanması ile birlikte su seviyesi zamanla düşerek hidrolik sıçramanın şiddetini azalmaktadır.

Daralma bölgesinin membasında nehir rejimine geçen akım, kesitin en dar bölgesini oluşturan boğaz kısmının yaklaşık orta noktasında kritik derinlikten geçerek genişleyen kısımda tekrar sel rejimine geçmektedir. Daralma bölgesinin varlığı ile kanal boyunca farklı akım rejimlerinin ve rejim geçişlerinin olduğu zamanla değişen karmaşık bir akım ortamının oluştuğu gözlenmiştir. Kanal boyunca oluşan akım rejimleri Şekil $3 t=3.5 \mathrm{~s}$ anında verilmiştir. Şekilde sel rejimine sahip bölgeler resmin alt tarafında kırmızı şerit, nehir rejimine sahip bölgeler sarı şerit ile temsil edilmiştir.

Rezervuarda ve daralmanın membasındaki bir bölgede akım nehir rejimindedir ve yaklaşık olarak baraj aksının olduğu bölgede ve boğaz kısmının orta noktasında akım kritik derinlikten geçerek sonrasındaki kısımlarda sel rejimi meydana gelmektedir (sarı şeritten kırmızıya geçiş). Sel rejiminden nehir rejimine geçiş ise hidrolik siçrama ile mümkün olmaktadır (kırmızı şeritten sarıya geçiş). 

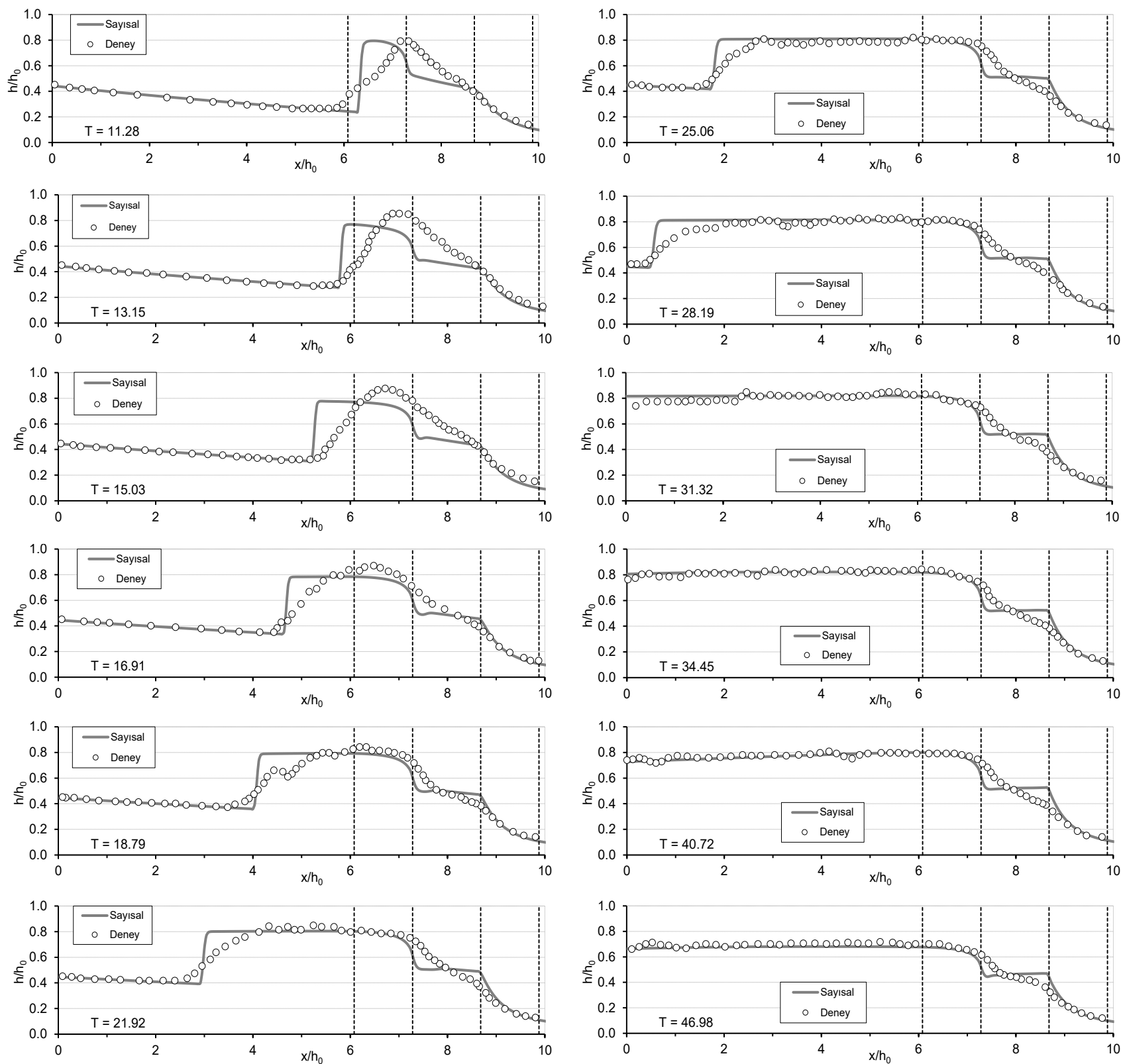

Şekil 4. Deneysel ve nümerik su yüzü profilleri sonuçlarının karşılaştırılması

$\mathrm{Bu}$ durum negatif dalganın ön kısmında oluşmakta ve memba yönünde ilerlemektedir. Değişken akım için deneysel olarak akım rejimlerinin belirlenmesi zordur. Bunula birlikte sayısal modeller ile rejim değişiklikleri ve Froude sayısının belirlenmesi kolaylıkla hesaplanabilmektedir [22-23].

Ayrıca daralma sebebiyle oluşan kabarmanın memba tarafına doğru ilerlemesi $T=15.03, T=18.79$ ve $T=31.32$ zamanlarına ait grafikler incelendiğinde görülmektedir. Mansap tarafinda meydana gelen daralma sebebiyle kanal boyunca memba ve mansap taraflarında rejim geçişlerinin bulunduğu karmaşık bir akım ortamı oluşmuştur. Bu nedenle laboratuvar ortamında oluşturulan deney ortamının nümerik modelin çözüm yeteneklerinin doğrulanabilmesi için iyi bir test ortamı olduğu düşünülmüştür.
Hidrolik sıçramanın oluşmaya başladığı ve negatif dalganın membaya doğru ilerlediği $T=11.28, T=15.03, T=18.79$ ve $T=25.06$ grafiklerinde kabarma dalgasının önünde süreksizlikler olduğu ve sonuçlar arasındaki uyumun bu bölgelerde azaldığı görülmektedir. Sığ su denklemleri, hiperbolik karakterli kısmi diferansiyel denklemlerdir. Hidrolik sıçrama gibi su yüzeyinde meydana gelen şok dalgalarından dolayı bu denklemlerin çözümlerinde süreksizlikler bulunmaktadır. Sı̆̆ su denklemlerinin doğası gereği oluşan bu süreksizliklerin çözümünde Riemann çözücülerden yararlanılmaktadır. Denklemlerin türetilmesinde düşey ivme bileşenleri ihmal edilip, basınç dağılımının hidrostatik olduğu kabul edilmektedir. Ancak bu varsayım, daralma bölgesinde taşkın dalgasının geçişi esnasında, su seviyesinin kabardığı negatif dalganın oluştuğu 
kısımda ve kanalın en dar boğazının başladığı ve bittiği noktalar gibi su yüzeyinde meydana gelen eğriliklerin olduğu durumlarda geçerli olmamaktadır.
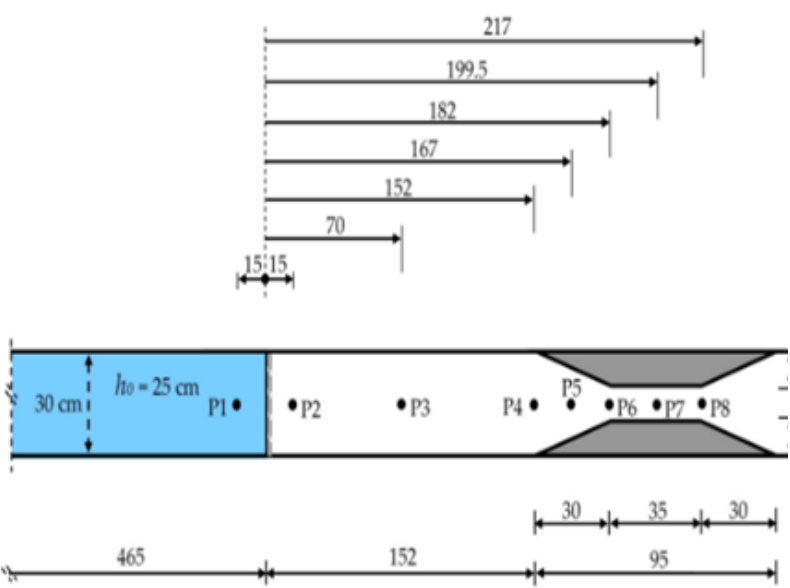

Şekil 5. Ölçüm noktalarının konumları [22]

Deney ve sayısal sonuçlara ait su yüzü profilleri karşılaş̧ırıldığında bu durumlar dışında $\mathrm{sığ} \quad$ su denklemlerinin su seviyelerini başarılı bir biçimde belirleyebildiği görülmektedir. Ayrıca, hareketli bir hidrolik sıçrama olarak düșünülen negatif dalga önü sayısal çözümde bir şok dalgası olarak öngörüldüğünden bu bölgede de süreksizlik şeklinde uyumsuzluklar göze çarpmaktadır. Buna karşın deneysel çalışmadaki negatif dalganın yayılma hızının başlangıç aşaması dışında sayısal çözüm ile uyumlu olduğu göze çarpmaktadır.

Kanal boyunca biri rezervuarda olmak üzere toplam 8 farklı noktada deney görüntülerinden sanal derinlik ölçer kullanılarak su seviyelerinin zamana bağlı değişimleri elde edilmiştir. Şekil 5'te ölçüm noktalarının konumları gösterilmiştir. Şekil 6'da tüm ölçüm noktalarında (P1-P8) deney ve sayısal sonuçlar arasında zamana bağlı su seviyesi değișimlerinin boyutsuz karşılaştırılması görülmektedir. Genel olarak kesitin en dar kısmın başladığ 1 P6 ve P8 noktaları dışında deneysel ölçümler ile sayısal veriler arasında oldukça iyi bir uyumun olduğu görülmektedir. Sayısal çözümde P6 noktasında su seviyeleri deney sonuçlarının altında, P8 ölçüm noktasında ise üstünde çıkmaktadır. Su seviyesinde ani değişimlerin olduğu ve yüzey eğriliğinin çok fazla olduğu bu noktalarda düş̧ey ivme bileșenleri baskın olduğundan dolayı hidrostatik basınç dağılımı kabulü geçerli olmadığından bu ölçüm noktalarında sayısal sonuçlarla deney sonuçları arasında uyumsuzluk olduğu düşünülmektedir. Bu durum Şekil 4 'de verilen su yüzü profili grafiklerinde de en dar kesitin başlangıç $\left(x / h_{0}=7.28\right)$ ve bitiş $\left(x / h_{0}=8.68\right)$ noktalarında da açıkça görülmektedir. $\mathrm{Bu}$ etkilerin dahil edildiği RONS denklemlerine dayalı literatürdeki çözümlerde sı̆̆ su denklemlerinin sayısal çözümünün aksine deney sonuçları ile oldukça iyi bir uyum olduğu gözlenmiştir [22].

Barajı temsil eden kapağın ani bir şekilde kalkmasıyla birlikte rezervuarda barajin hemen membasında bulunan P1 noktasında $T=5$ anına kadar ani bir seviye düşmesi, barajın hemen mansabında bulunan P2 noktasında ise bir yükselme gözlenmektedir. Her iki nokta için de bu andan sonra debinin zamanla azalmasıyla birlikte yaklaşık $T=30$ anına kadar daha su seviyesindeki değişim yavaş seyretmektedir. Yansıyan dalganın P1 ve P2 noktalarına tekrar ulaşmasıyla birlikte (yaklaşık olarak $T=30$ ) su seviyesinde tekrar ani bir artış gözlenmektedir. Bu ana kadar sayısal ve deneysel sonuçlar arasında oldukça iyi bir uyum olduğu görülmektedir. Bununla birlikte P1 noktasında su seviyesinin azalması esnasında ( $T=0-5$ anları arası) sayısal çözümün deney ölçümlerinden biraz daha aşağı seviyede kaldığı diğer bir ifade ile sayısal çözümde rezervuarın daha erken boşaldığ 1 görülmektedir. Negatif dalganın geçişi ile birlikte kesitlerde maksimum su seviyelerinin meydana geldiği $(T=35)$ ve sayısal sonuçların deney sonuçlarının üzerinde su seviyesine sahip oldukları gözlenmiştir. Sayısal çözümde negatif dalga önünün bir miktar daha hızlı hareket ettiği ve hidrolik sıçrama şeklinde ilerleyen dalga önündeki süreksizlikten dolayı daha dik bir şekilde meydana geldiği görülmektedir. Rezervuarın sonlu bir uzunluğa sahip olmasından dolayı debinin zamanla azalması ve daralan kesitten suyun tahliye edilmesi ile birlikte ölçüm alınan noktalardaki su seviyelerinde zamanla azalan $(T=35-85)$ bir düşüş görülmektedir. $\mathrm{Bu}$ aşamada deneysel ölçümlerde hidrolik sıçramanın da etkisiyle su yüzeyinde küçük salınımlar meydana gelmesine karşın sayısal çözümde su yüzeyinin daha düzgün bir profile sahip olduğu göze çarpmaktadır.

Grafiklerde su seviyeleri alçalmakta iken kanal memba ucundan yansıyan kabarma dalgasının ölçüm alınan kesitlere tekrar ulaşmasıyla birlikte bu noktalarda su seviyelerinin tekrar hizla yükseldiği $(T>85)$ ve su yüzeyinde dalgalanmaların meydana geldiği görülmektedir. Sayısal çözümde dalganın önünün bu noktaya tekrar gelme zamanı yaklaşık aynı olmakla birlikte sayısal modelin bu dalgalanmaları tam olarak belirleyemediği ve su seviyelerinin dalgalanmaların ortalama çizgisi şeklinde hareket ettiği görülmektedir. Benzer akım davranışlarının diğer ölçüm noktalarında da meydana geldiği göze çarpmaktadır. Buna karşın, ölçüm alınan noktalarda daralma bölgesine yaklaştıkça baraj yıkılması taşkın dalgasının bu noktalara ulaşması ile yansıyan dalganın ulaşması arasında geçen sürenin kısa olması sebebiyle kesintisiz ani bir seviye yükselmesi gözlenmektedir. Bu durum özellikle daralmanın başlangıcı olan P4 ve P5 noktalarında belirgin biçimde göze çarpmaktadır $(\mathrm{T}=5-15)$. Bu kısımlarda sonuçlar arasında eğilim olarak uyum olsa da; sayısal çözümün deneysel verilere göre pik değerleri biraz daha aşağı bir seviyede belirlediği ve pik değerlerin oluşma süresini biraz daha erken olarak tahmin ettiği görülmektedir.

Seviye değişiminin yavaş bir şekilde devam ettiği $(T=20$ 80) anlarda da sayısal çözüme ait veriler deneysel verilere göre biraz daha düşük bir seviyede seyretmiştir. Ölçüm alınan P6, P7 ve P8 noktalarında ise daralma sebebiyle oluşan yansıma dalgası hissedilmemiş ve sürekli bir şekilde seviye artı̧ı meydana gelmiştir.

Sığ su denklemlerine dayalı sayısal çözümün akımın davranışını, yansıyan dalganın oluştuğu ve taşkın dalgasının daralan kesitten geçtiği anlar hariç genel olarak doğru tahmin ettiği görülmektedir. Bahsi geçen kısımlarda deneysel ve sayısal verilerin uyuşmamasının, su yüzü profillerine ait 

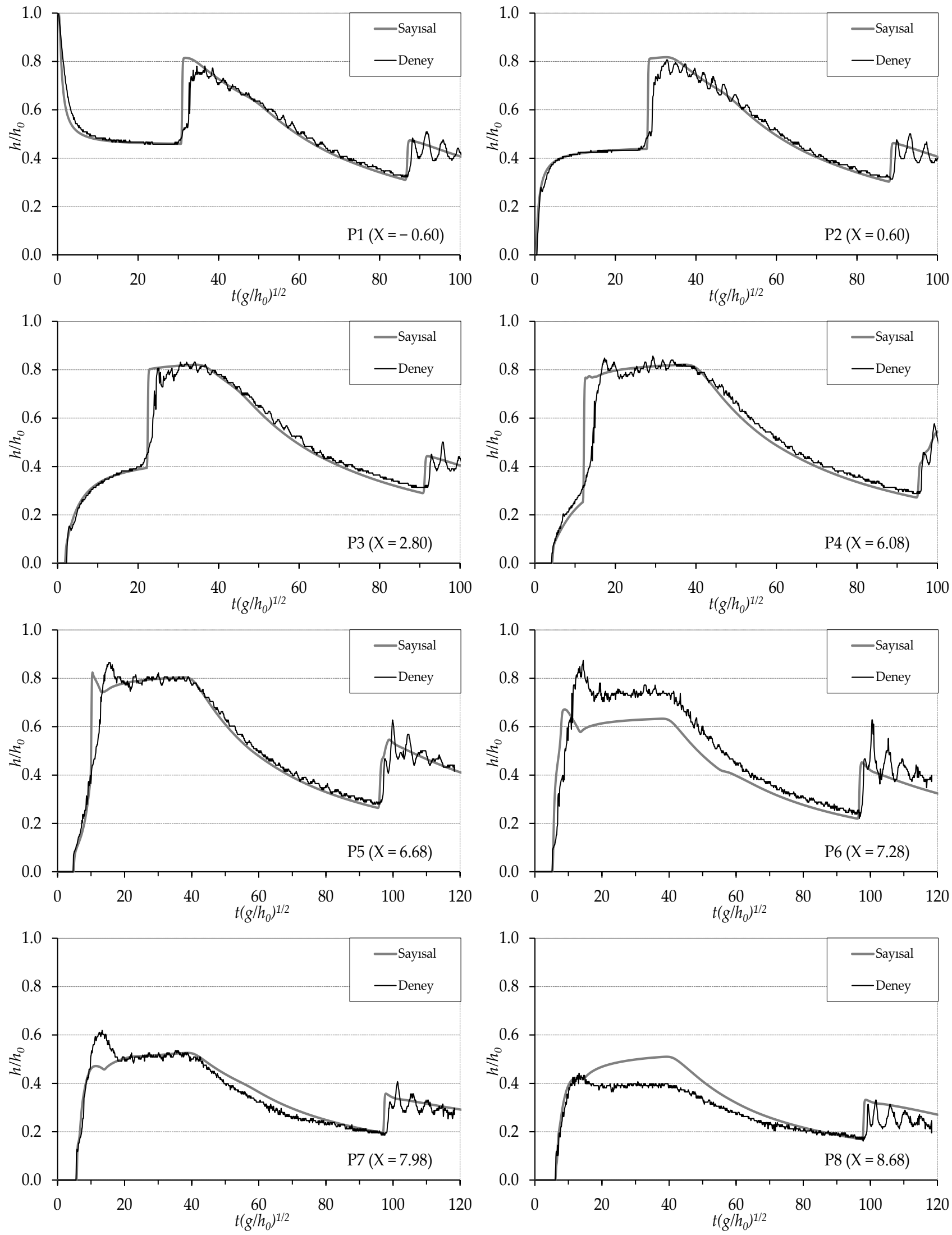

Şekil 6. Deneysel ve nümerik noktasal ölçüm sonuçlarının karşılaştırılması 
veriler yorumlanırken de bahsedildiği gibi sığ su denklemleri ile problem çözülürken düşey ivme bileşenlerinin ihmal edilip, basınç dağılımının hidrostatik olduğunun kabul edilmesinden kaynaklandığı düşünülmektedir. Gerçekte ise dalga yansıması veya kesit daralması gibi durumlarda yüzey eğrilikleri oluşmakta ve basınç dağılımının hidrostatik olması mümkün olmamaktadır. $\mathrm{Bu}$ durum deneysel ve sayısal verilerin tutarsız olduğu kısımların temel sebebi olmaktadir.

Genel olarak bakıldığında deneysel olarak elde edilen dalga önünün ilerleme hızlarının ve su yüzü profillerinin tam Riemann çözücü ile yapılan sayısal çözüm sonuçları ile iyi bir uyum içerisinde oldukları söylenebilir.

Yapılan çalışmada, yatay dikdörtgen bir kanalda rijit yatak koşullarında, mansapta trapez daralma olması durumu için ideal koşullara sahip baraj yıkılması problemi iki boyutlu sığ su denklemleri kullanılarak ele alınmıştır. Gerçek arazi verilerinin bulunmamasından dolayı baraj yıkılması problemine ait sayısal modellerin doğrulanması için deneysel çalışmalardan yararlanılmaktadır. Gerçekte baraj yıkılması problemi arazi topoğrafyasında oyulma, yığılmaların olduğu ve taşkının sürüklediği enkaz etkilerinin bulunduğu daha karmaşık bir yapıya sahiptir. Bunun yanında, taşkın güzergâhı üzerinde topografyada daralmalar, taban eğimlerinde ani değişimlerin olması; yerleşim birimlerinin, yolların, köprülerin vb. varlığı ve topoğrafyadaki farklı bitki örtülerinin bulunması olası su seviyeleri ve dalga yayılım hızları gibi akım karakteristiği üzerinde önemli etkilere sahip olacaktır. Ayrıca bu etkenler pürüzlülük değerlerinin doğru belirlenmesinde güçlüklere de neden olacaktır. Bunula birlikte, dar vadilerde baraj yıkılması analizlerinin yapılabilmesi için sı̆̆ su denklemlerine ait 1 boyutlu denklemler kullanılabilirken, taşkının geniş arazilerde olması durumunda Giriș kısmında da belirtildiği gibi arazi şartları göz önüne alınarak 2 boyutlu çözümlere de ihtiyaç duyulacaktır [24]. Ayrıca, taşkın güzergahı üzerinde köprü gibi yapıların varlığı durumunda hassas sonuçlar istenildiğinde türbülans modellerini de içeren 3 boyutlu sayısal çözümlere gereksinim duyulacaktır. Baraj yıkılması taşkınları gibi büyük ölçekli gerçek arazi topoğrafyasına uygulanacak 3 boyutlu modellerde çözüm süreleri oldukça uzun zaman alacak ve yüksek çözüm kapasitesine sahip bilgisayar sistemlerinin kullanılması gerekecektir. Buna karşın, topoğrafya iki boyutlu sığ su denklemleri ile modellenirken köprü gibi engellerin civarında akımın 3 boyutlu RONS denklemleri kullanılarak modellendiği hibrit yöntemlere başvurulması problemin çözüm süresini önemli ölçüde azaltabilecektir. Sığ su denklemlerinin sağladığı en önemli avantaj sayısal modele ait çözüm sürelerinin 3 boyutlu modellere kıyasla daha kısa olmasıdır [25]. Sonuç olarak, baraj yıkılması taşkın analizi konusunda güvenilir modellerin yapilabilmesi ve hassas sonuçların elde edilebilmesi için bu etkilerin mutlaka dikkate alınması ve sayısal modellerin bu koşulları içeren kapsamlı deneysel çalışmalarla doğrulanması gerekecektir.

\section{Sonuçlar}

Eğimsiz ve kuru yatak şartlarında baraj yıkılması sonucu oluşan taşkın dalgasının, mansap tarafında trapez şekilde daralan kesit olması durumunda yayılmasının deneysel verileri görüntü işleme metodu ile elde edilmiştir.

Mansapta bulunan kesit daralmasının akıma önemli bir etkisi olduğu gözlenmiştir. Akımın bir kısmı daralmış kesitten geçerken bir kısmının daralma karşısında kabardığı ve membaya doğru negatif şok dalgasının yayıldığ görülmüştür. Negatif dalga yayılmasına ait su yüzü profilleri görüntü işleme metodu ile belirlenmiş ve bu yöntemin sığ su denklemlerine dayalı ve tam Riemann çözücü kullanılarak çözüm yapılan BASEMENT yazılımından elde edilen sayısal sonuçlar ile kabul edilebilir uyum içerisinde olduğu gözlemlenmiştir.

Ayrıca 3 boyutlu RONS denklemlerini kullanan sayısal analiz yöntemleri yerine, daha az gelişmiş bilgisayar teknolojisi ve hesaplama gücü gereksinimi sayesinde daha kısa sürede çözüm yapabilen 2 boyutlu sı̆̆ su denklemlerini kullanan yazılımların da karmaşık hidrolik problemlerden biri olan baraj yıkılması taşkın dalgalarının analizlerinde iyi bir alternatif olarak kullanılabileceği görülmüştür. Öte yandan daha düşük bilgisayar teknolojisi ihtiyacının, daha düşük maliyet anlamına gelmesinin de önemli bir avantaj olduğu düşünülmüştür.

\section{Çıkar çatışması}

Yazarlar çıkar çatışması olmadığını beyan etmektedir.

\section{Benzerlik oranı (iThenticate): $\% 5$}

\section{Kaynaklar}

[1] P. Garcia-Navarro, A. Fras and I. Villanueva, Dambreak flow simulation: some results for onedimensional models of real cases, Journal of Hydrology, 216 (3), 227-247, 1999. https://doi.org/ 10. 1016/S0022-1694(99 )00007-4.

[2] F. Aureli, P. Mignosa and M. Tomirotti, Numerical simulation and experimental verification of dam-break flows with shocks. Journal of Hydraulic Research, 38 (3), 197-206, 2000. https://doi.org/10.1080/ 0022168 0009498337.

[3] S. Kocaman, Baraj yıkılması probleminin deneysel ve teorik incelenmesi. Doktora Tezi, Çukurova Üniversitesi Fen Bilimleri Enstitüsü, Adana, Türkiye, 2007.

[4] P. Brufau and P. Garcia-Navarro, Two-dimensional dam break flow simulation, International Journal for Numerical Methods In Fluids, 33 (1), 35-57, 2000. https://doi.org/10.1002/(SICI)10970363(20000515)33: 1<35:AID-FLD999>3.0.CO;2-D .

[5] Q. Liang, Simulation of shallow flows in nonuniform open channels, Journal of Fluids Engineering, 130 (1), 011205, 2008. https://doi.org/10.1115/1.2829593.

[6] F. Aureli, A. Maranzoni, P. Mignosa and C. Ziveri, Dam-break flows: acquisition of experimental data through an imaging technique and 2D numerical modeling, Journal of Hydraulic Engineering, 134 (8), 
1089-1101, 2008. https://doi.org/10.1061/(ASCE) 0733 -9429(2008) 134:8(1089).

[7] H. Ozmen-Cagatay ve S. Kocaman, Dam-break flows during initial stage using SWE and RANS approaches, Journal of Hydraulic Research, 48 (5), 603-611, 2010. https://doi.org/10.1080/00221686.2010.507342.

[8] S. Soares-Frazão and Y. Zech, Experimental study of dam-break flow against an isolated obstacle, Journal of Hydraulic Research, 45 (sup1), 27-36, 2007. https://doi .org/10.1080/00221686.2007.9521830.

[9] K. Dal, Eğimli kanalda ardışık baraj yıkılmasının deneysel ve sayısal incelenmesi, Yüksek Lisans Tezi, İskenderun Teknik Üniversitesi Mühendislik ve Fen Bilimleri Enstitüsü, Hatay, Türkiye, 2018.

[10] A. Yılmaz, Akışkan-yapı etkileşimi problemlerinin deneysel ve sayısal incelenmesi, Yüksek Lisans Tezi, İskenderun Teknik Üniversitesi Mühendislik ve Fen Bilimleri Enstitüsü, Hatay, Türkiye, 2019.

[11] B. Erdoğan, Dikdörtgen tank içerisindeki çalkantı hareketinin deneysel ve nümerik olarak incelenmesi, Yüksek Lisans Tezi, İskenderun Teknik Üniversitesi Mühendislik ve Fen Bilimleri Enstitüsü, Hatay, Türkiye, 2018.

[12] S. Kocaman, H. Ozmen-Cagatay, The effect of lateral channel contraction on dam break flows: laboratory experiment, Journal of Hydrology, 432, 145-153, 2012. https://doi.org/10.1016/j.jhydrol.2012.02.035.

[13] S. Kocaman, C. Ateş ve K. Dal, Dikdörtgen kesitli kanalda kuru yatak üzerinde yayılan baraj yıkılması akımının sığ su denklemleri ile modellenmesi, 2nd International Symposium on Innovative Approaches in Scientific Studies, Samsun, Türkiye, 30 Kasım - 02 Aralik 2018.

[14] Y. Zhang and P. Lin, An improved SWE model for simulation of dam-break flows. Institution of Civil Engineers-Water Management, 169 (6), 260-274, 2016. https://doi.org/10.1680/wama.15.00021.

[15] S. Kocaman and H. Ozmen-Cagatay, Investigation of dam-break induced shock waves impact on a vertical wall. Journal of Hydrology, 525, 1-12, 2015. https://doi.org/10.1016/j.jhydrol.2015.03.040.

[16] X. G. Zheng, J.H. Pu, R.D. Chen, X.N. Liu and S.D. Shao, A novel explicit-implicit coupled solution method of SWE for long-term river meandering process induced by dam break. Journal of Applied
Fluid Mechanics, 9 (6), 2647-2660, 2016. https://doi.org/doi:10.29252/jafm.09.06.25969

[17] O. Castro-Orgaz and H. Chanson, Undular and broken surges in dam-break flows: a review of wave breaking strategies in a boussinesq-type framework, Environ mental Fluid Mechanics, 20, 1383-1416, 2020. https://doi .org /10.1007/s10652-020-09749-3

[18] Y. Wu, L. Tian, M. Rubinato, S. Gu, T. Yu, Z. Xu and Q. Zhao, A new parallel framework of SPH-SWE for dam break simulation based on OpenMP, Water, 12 (5), 1395, 2020. https://doi.org/10.3390/w12051395

[19] S. Kocaman ve K. Dal, A new experimental study and SPH comparison for the sequential dam-break problem. Journal of Marine Science and Engineering, 8 (11), 905, 2020. https://doi.org/10.3390/jmse8110905

[20] W. Bechteler, M. Nujic and A. J. Otto, Program package FLOODSIM and its application, Advances in Hydro-Science and-Engineering, 762-767, 1993.

[21] R. Faeh, R. Mueller, P. Rousselot, R. Veprek, D Vetsch, C. Volz, L. Vonwiller, L., Farshi, D, BASEMENT - basic simulation environment for computation of environmental flow and natural hazard simulation, VAW, ETH Zurich. http://www.baseme nt.ethz.ch, (Erişim tarihi: Temmuz, 27, 2017).

[22] S. Kocaman, H. Güzel, S. Evangelista, H. OzmenCagatay ve G. Viccione, Experimental and numerical analysis of a dam-break flow through different contraction geometries of the channel, Water, 12 (4) 1124, 2020. https://doi.org/10.3390/w12041124

[23] H. Ozmen-Cagatay ve S. Kocaman, Dam-break flow in the presence of obstacle: experiment and CFD simulation. Engineering Applications of Computational Fluid Mechanics 5(4), 541-552, 2011. https://doi.org/1 $0.1080 / 19942060.2011 .11015393$

[24] B.N. İşcen, N. Öktem, B. Yılmaz ve İ. Aydın, Sı ̆̆ akım denklemlerinin hidrolikte kullanılması üzerine değerlendirmeler, İMO Teknik Dergi, 28 (1), 77477764, 2017.

[25] S. Kocaman, S. Evangelista, H. Guzel K. Dal, A. Yilmaz, G. Viccione. Experimental and numerical investigation of 3D dam-break wave propagation in an enclosed domain with dry and wet bottom. Applied Sciences, 11(12),5638, 2021. https://doi.org/10.3390/app11125638 